\title{
Plant odorants interfere with detection of sex pheromone signals by male Heliothis virescens
}

\author{
Pablo Pregitzer ${ }^{1}$, Marco Schubert ${ }^{2,3}$, Heinz Breer ${ }^{1}$, Bill S. Hansson ${ }^{2}$, Silke Sachse $^{2 \dagger}$ and \\ Jürgen Krieger ${ }^{1 * t}$ \\ 1 Institute of Physiology, University of Hohenheim, Stuttgart, Germany \\ 2 Department of Evolutionary Neuroethology, Max Planck Institute for Chemical Ecology, Jena, Germany \\ ${ }^{3}$ Department of Biology, Chemistry and Pharmacy, Institute of Biology/Neurobiology, Free University Berlin, Berlin, Germany
}

Edited by:

Dieter Wicher, Max Planck Institute for Chemical Ecology, Germany

\section{Reviewed by:}

Sylvia Anton, Institut National de la

Recherche Agronomique, France

Bente G. Berg, Norwegian

University of Science and

Technology, Norway

Thomas Baker, The Pennsylvania

State University, USA

\section{*Correspondence:}

Jürgen Krieger, Institute

of Physiology (230), University

of Hohenheim, Garbenstraße 30,

70599 Stuttgart, Germany.

e-mail:krieger@uni-hohenheim.de

${ }^{\dagger}$ Silke Sachse and Jürgen Krieger share the last authorship
In many insects, mate finding relies on female-released sex pheromones, which have to be deciphered by the male olfactory system within an odorous background of plant volatiles present in the environment of a calling female. With respect to pheromone-mediated mate localization, plant odorants may be neutral, favorable, or disturbing. Here we examined the impact of plant odorants on detection and coding of the major sex pheromone component, (Z)-11-hexadecenal (Z11-16:Ald) in the noctuid moth Heliothis virescens. By in vivo imaging the activity in the male antennal lobe $(A L)$, we monitored the interference at the level of olfactory sensory neurons (OSN) to illuminate mixture interactions. The results show that stimulating the male antenna with Z11-16:Ald and distinct plant-related odorants simultaneously suppressed pheromone-evoked activity in the region of the macroglomerular complex (MGC), where Z11-16:Ald-specific OSNs terminate. Based on our previous findings that antennal detection of Z11-16:Ald involves an interplay of the pheromone binding protein (PBP) HvirPBP2 and the pheromone receptor (PR) HR13, we asked if the plant odorants may interfere with any of the elements involved in pheromone detection. Using a competitive fluorescence binding assay, we found that the plant odorants neither bind to HvirPBP2 nor affect the binding of Z11-16:Ald to the protein. However, imaging experiments analyzing a cell line that expressed the receptor HR13 revealed that plant odorants significantly inhibited the Z11-16:Ald-evoked calcium responses. Together the results indicate that plant odorants can interfere with the signaling process of the major sex pheromone component at the receptor level. Consequently, it can be assumed that plant odorants in the environment may reduce the firing activity of pheromone-specific OSNs in $\mathrm{H}$. virescens and thus affect mate localization.

Keywords: pheromone detection, antennal lobe, pheromone receptor, pheromone binding protein, olfaction

\section{INTRODUCTION}

The ability of many insect species to use plant volatiles and pheromones to locate food, sexual partners, and appropriate egglaying places is crucial for survival and reproduction (Zwiebel and Takken, 2004; Vosshall, 2008; Carey and Carlson, 2011; Hansson and Stensmyr, 2011). The remarkable pheromone detection system of male moths (Schneider, 1992; Hansson, 1995) allows them to recognize female-released sex pheromone blends from long distances (David et al., 1983; Vickers and Baker, 1997); in addition, it triggers and controls upwind flight behavior and guides the sexual partner to the calling female (Vickers et al., 1991; Vickers, 2006; Carde and Willis, 2008).

Components of female sex pheromone blends are detected by specialized sensilla on the male antenna (Almaas and Mustaparta, 1991; Baker et al., 2004). These porous, hair-like structures

Abbreviations: $\mathrm{AL}$, antennal lobe; $\mathrm{HR}$, Heliothis virescens receptor; $\mathrm{PBP}$, pheromone binding protein; Z11-16:Ald, (Z)-11-hexadecenal; OSNs, olfactory sensory neurons; Ph-OSNs, pheromone-responsive olfactory sensory neurons. house the dendrites of pheromone-responsive olfactory sensory neurons ( $\mathrm{Ph}-\mathrm{OSN}$ ) bathed in sensillum lymph containing a high concentration of pheromone binding proteins (PBP) (Vogt and Riddiford, 1981; Steinbrecht and Gnatzy, 1984; Zhang et al., 2001). Specific PBPs take distinct pheromone molecules from the air and transfer them through the lymph toward specific pheromone receptors (PRs) in the dendritic membrane of $\mathrm{Ph}$ OSNs (Leal, 2003; Vogt, 2003; Grosse-Wilde et al., 2006, 2007; Forstner et al., 2009). The Ph-OSNs for different pheromone components are endowed with specific PRs (Krieger et al., 2004; Nakagawa et al., 2005; Grosse-Wilde et al., 2010; Wanner et al., 2010) and converge their axons into separate compartments of the macroglomerular complex (MGC), the male-specific pheromone-processing center within the antennal lobe (AL) (Hansson et al., 1992; Berg et al., 1998; Hansson and Anton, 2000). In contrast, signals from general odorants, e.g., plant volatiles, are detected by general OSNs and transferred to sexually isomorphic ordinary glomeruli in the AL (Galizia et al., 2000; Hansson et al., 2003). 
When they are released the female-produced sex pheromones are embedded within a background of general odorants, mainly plant volatiles. The air concentration of odorants depends on various environmental parameters: the abundance of vegetation, time of day, and weather (Kesselmeier and Staudt, 1997; Müller et al., 2002). Therefore, a male's sex pheromone detecting system is exposed simultaneously to mixtures of pheromone components and general odorants at varying ratios. The highest concentrations of both pheromone and plant odorants are likely to be present near to the calling female, which is often situated on a host plant. Although many studies of insect olfaction have addressed antennal detection and central coding of single compounds, as well as of mixtures of plant odorants or of pheromone blends, (e.g., Galizia and Menzel, 2000; Galizia et al., 2000; Hallem and Carlson, 2006; Lei and Vickers, 2008; Wang et al., 2010; Kuebler et al., 2012), few studies have examined pheromone/plant odorant mixtures. Recent electrophysiological studies on the pheromone sensilla of Heliothis virescens (Hillier and Vickers, 2011), Spodoptera littoralis (Party et al., 2009) and Agrotis ipsilon (Deisig et al., 2012) have found that the firing activity of $\mathrm{Ph}$-OSNs to specific pheromone components was suppressed when plant odorants were co-applied. In contrast, an earlier study on Helicoverpa zea indicated enhancement of the pheromone-evoked spike activity of Ph-OSNs in the presence of plant odorants (Ochieng et al., 2002). Stimulation of the antenna with the plant odorant heptanal was found to reduce the pheromone response in the MGC of Agrotis ipsilon on both the input (Ph-OSNs) and output side (projection neurons, PNs) (Chaffiol et al., 2012; Deisig et al., 2012); conversely, in the silk moth Bombyx mori, sex pheromone responses in PNs of the MGC were enhanced in the presence of the host plant odor Z3-hexenol (Namiki et al., 2008).

Current data indicate that the interference of plant odorants with pheromone responses may appear already at the level of antennal sensilla-suppressing or enhancing Ph-OSN firing activity which is conveyed to the AL. The molecular targets at which plant odorants may interfere with pheromoneinduced activities of OSNs are unknown, but key elements involved in pheromone detection, such as PBPs in the sensillum lymph or PRs in the dendrites of $\mathrm{Ph}-\mathrm{ORNs}$, are considered as candidates (Party et al., 2009; Deisig et al., 2012). Our previous studies have indicated that an interplay of the PBP HvirPBP2 and the PR HR13 is important for eliciting cellular responses by the major sex pheromone component Z11-16:Ald (Grosse-Wilde et al., 2007). In the present study we set out to explore if plant volatiles may interact with any of these key elements. In order to identify plant odorants, which may affect pheromone detection in $H$. virescens we performed in vivo imaging experiments monitoring pheromone-evoked activity in the so-called cumulus region of the MGC, where Z11-16:Ald-specific OSNs terminate (Galizia et al., 2000). Using a fluorescencebased competitive binding assay we examined how identified plant odorants and pheromone/plant odorant mixtures bind to HvirPBP2. Furthermore, a cell line expressing the PR HR13 was employed in fura-2-based calcium imaging studies to test whether plant odorants interfere with Z11-16:Ald detection at the level of the PR.

\section{MATERIALS AND METHODS ANIMALS}

H. virescens pupae were kindly provided by Bayer CropScience, Frankfurt, Germany. Pupae were sexed and allowed to develop at room temperature. After emergence, moths were fed on $10 \%$ sucrose solution.

\section{PHEROMONE AND PLANT ODORANTS}

(Z)-11-hexadecenal (Z11-16:Ald) was purchased from Fluka or Bedoukian. Plant odorants ( $\beta$-caryophyllene, geraniol, Z3hexenol, isoamyl acetate, linalool, linalyl acetate) were purchased from Fluka, Sigma, and Merck at the highest purity available. $\beta$-caryophyllene, geraniol, Z3-hexenol, and linalool were selected because of their physiological and ecological relevance to heliothine moths. For these chemicals previous studies on male and female $H$. virescens have identified responsive OSNs on the antenna, processing glomeruli in the AL or effects on behavior (De Moraes et al., 2001; Skiri et al., 2004; Hillier et al., 2005; Rostelien et al., 2005; Hillier and Vickers, 2007). Isoamyl acetate was chosen as a typical fruit odor. Linalyl acetate was selected because it is chemically related to linalool and emitted as a principle component from many flowers and spice plants. For optical imaging experiments, plant odorants were diluted in mineral oil (Sigma-Aldrich) to a concentration of 1:10 (v/v) which equates to 85-90 $\mu \mathrm{g} / \mu \mathrm{l}$. The pheromone component Z11-16:Ald was diluted to a final concentration of $1 \mu \mathrm{g} / \mu \mathrm{l}$.

\section{OPTICAL IMAGING OF THE ANTENNAL LOBE}

Moths were 1- to 5-day-old male $H$. virescens. Animals were gently pushed into a $1000 \mu \mathrm{l}$ pipette whose tip had been cut open and then fixed with dental wax. After the scales were removed, the labial palps and proboscis were fixed to reduce movement artifacts. A window was cut into the head cuticle between the compound eyes. Glands and trachea were carefully removed to get access to the brain. A fluorescent calcium indicator (Calcium Green-1 or 2 AM, Invitrogen) was dissolved in Ringer solution $(150 \mathrm{mM} \mathrm{NaCl}, 3 \mathrm{mM} \mathrm{KCl}, 3 \mathrm{mM} \mathrm{CaCl} 2,25 \mathrm{mM}$ sucrose, $10 \mathrm{mM}$ TES buffer, pH 6.9) with 6\% Pluronic F-127 (Invitrogen) to a concentration of $30 \mu \mathrm{mol}$. The brain was incubated with $\sim 20 \mu \mathrm{l}$ of this solution at $4^{\circ} \mathrm{C}$. After incubation for $60 \mathrm{~min}$, the brain was rinsed several times with Ringer solution.

Imaging experiments were performed using a Till Photonics imaging setup (TILL imago, Till Photonics GmbH) with a CCDcamera (PCO imaging, Sensicam) and a fluorescence microscope (Olympus, BX51WI) equipped with a $20 \times$ water immersion objective (NA 0.95, XLUM Plan FI, Japan). Calcium Green ${ }^{\mathrm{TM}}$ was excited at $475 \mathrm{~nm}$ (500 nm SP, xenon arc lamp, Polychrome V, Till Photonics), and fluorescence was detected at 490/515 nm (DCLP/LP). The whole setup was placed on a dumping table. Fourfold binning on the CCD-camera chip gave a resolution of $1.25 \mu \mathrm{m} /$ pixel with an image size of $344 \times 260$ pixels.

Six $\mu$ l of plant odorants (i.e., $510-540 \mu \mathrm{g}$ ) or $10 \mu \mathrm{l}$ of pheromone component (i.e., $10 \mu \mathrm{g}$ ) was pipetted on a filter paper (12 $\mathrm{mm}$ diameter), which was inserted into a glass pipette; these were renewed every day. A stimulus controller (Syntech, Stimulus Controller CS-55) was used to apply the odor in a continuous airstream, whose flow of $0.61 / \mathrm{min}$ was monitored by a flow 
meter (Cool Parmer). An acrylic glass tube guided the airflow to the moth's antenna. For mixture application, plant odorant and pheromone component were applied in two separate pipettes which were inserted into the continuous airstream (stimulus flow: $0.4 \mathrm{l} / \mathrm{min}$ ). In case of single odor application, the second pipette was empty. Each recording had a continuance of $10 \mathrm{~s}$ with an acquisition rate of $4 \mathrm{~Hz}$. Odors were applied after $2 \mathrm{~s}$ for $2 \mathrm{~s}$. Single moths were imaged for up to $1 \mathrm{~h}$, with interstimulus time intervals (ISI) of 1-3 min. The sequence of stimulations was randomized from insect to insect and repeated in a few cases to test for reproducibility of the odor-evoked activity patterns.

The imaging data were processed as previously described (Bisch-Knaden et al., 2012) using custom-written software in IDL (ITT Visual Information Solutions). To quantify odor-evoked calcium signals, we identified the cumulus because of its clear response to Z11-16:Ald and its proximity to the antennal nerve entrance. In each animal, the responses were normalized to the maximal response over all odorants. We defined the average of frames $10-18$ (i.e., $0.5 \mathrm{~s}$ after stimulus onset until $0.5 \mathrm{~s}$ after stimulus offset) as the odor-evoked signal intensity.

\section{EXPRESSION AND PURIFICATION OF $\boldsymbol{H}$. virescens PBP2}

The bacterial expression of $H$. virescens PBP2 (HvirPBP2) (Krieger et al., 1993) and purification of the protein from a periplasmic fraction of E. coli BL21 (DE3) was performed as described previously (Campanacci et al., 2001; Grosse-Wilde et al., 2007). Recombinant HvirPBP2 was delipidated to remove possible hydrophobic ligands, which may co-purify with PBP expressed in bacteria (Oldham et al., 2001), and finally dissolved in Ringer solution ( $138 \mathrm{mM} \mathrm{NaCl}, 5 \mathrm{mM} \mathrm{KCl}, 2 \mathrm{mM} \mathrm{CaCl}$, $1.5 \mathrm{mM} \mathrm{MgCl}_{2}, 10 \mathrm{mM}$ Hepes, $10 \mathrm{mM}$ glucose, $\mathrm{pH}$ 7.3). The protein concentration was determined using a spectrometer at $280 \mathrm{~nm}$ applying the absorption co-efficient determined by the ProtParam program (ExPASy molecular biology server: http:// www.expasy.org). Finally, the protein solution was aliquoted and stored at $-70^{\circ} \mathrm{C}$ until use. Once unfrozen, the HvirPBP2 solution was kept at $8^{\circ} \mathrm{C}$.

\section{COMPETITIVE FLUORESCENCE BINDING ASSAY WITH HvirPBP2}

To evaluate the binding of plant odorants to HvirPBP2 and an interference of plant odorants with pheromone binding, a competitive fluorescence binding assay that had previously been used to characterize ligand binding to various PBPs and odorant binding proteins (OBPs) of insects, including moth, flies, locust, and mosquitoes was applied (Campanacci et al., 2001; Ban et al., 2003; Zhou et al., 2004; Qiao et al., 2010).

Fluorescence emission spectra (360-600 nm) after excitation at $337 \mathrm{~nm}$ were recorded on a PerkinElmer LS 50B spectrofluorimeter using a quartz cuvette with a $1 \mathrm{~cm}$ light path fluorimeter in a right angle configuration and emission slit width of $5 \mathrm{~nm}$ were used. The binding of 1-N-phenylnapthylamine (1-NPN) to HvirPBP2 was determined by titrating $2 \mu \mathrm{M}$ protein with increasing concentrations of the chromophore dissolved in dimethyl sulfoxide (DMSO).

For competitive binding experiments, HvirPBP2 $(2 \mu \mathrm{M})$ in Ringer solution was loaded with $2 \mu \mathrm{M} 1-\mathrm{NPN}$. The change in 1 -NPN fluorescence was monitored after increasing amounts of
Z11-16:Ald, plant odorants, or combinations of both from stock solutions ( $10 \mathrm{mM}$ each; freshly prepared in methanol) were added to a final concentration of $10 \mu \mathrm{M}$. In control experiments, we observed no significant effects of the solvents in use (methanol for the pheromone component and plant odorants; DMSO for 1NPN) on 1-NPN binding to HvirPBP2. To evaluate how different compounds and pheromone/plant odorant mixtures bound to HvirPBP2, the maximum 1-NPN fluorescence at a given concentration was determined and related to the maximum 1-NPN fluorescence in the absence of competitor $(=100 \%)$. For data analysis and graphic plotting, the program GraphPad Prism version 4.0 (GraphPad Software, San Diego, CA, USA) was used. The $K_{\text {diss }}$ for Z11-16:Ald binding to HvirPBP2 was calculated according to $K_{\text {diss }}=[\mathrm{IC} 50] /\left(1+[1-\mathrm{NPN}] / \mathrm{K}_{1-\mathrm{NPN}}\right)$ with $[1-\mathrm{NPN}]=1-\mathrm{NPN}$ concentration and $\mathrm{K}_{1-\mathrm{NPN}}=1-\mathrm{NPN}$ dissociation constant for $\mathrm{PBP} / 1-\mathrm{NPN}$.

\section{CALCIUM IMAGING OF HR13-EXPRESSING CELLS}

To analyze the effect of plant-derived odorants on Z11-16:Ald detection by the PR HR13 (Krieger et al., 2004), we used a stable receptor-expressing cell line. The generation and functionality of HR13/Flp-In T-REx293/G $\alpha 15$ cells have been described previously (Grosse-Wilde et al., 2007). HR13/Flp-In T-REx293/G $\alpha 15$ cells were cultured using DMEM media (Invitrogen) supplemented with $10 \%$ fetal calf serum and either $100 \mathrm{mg} / \mathrm{L}$ hygromycin, $10 \mathrm{mg} / \mathrm{L}$ blasticidin, or $200 \mathrm{mg} / \mathrm{L}$ geneticin in regular alternation.

Calcium imaging experiments were performed as described previously (Grosse-Wilde et al., 2006, 2007; Forstner et al., 2009). Briefly, $48 \mathrm{~h}$ before imaging, $0.7 \times 10^{5}$ cells were plated onto poly-L-lysine coated glass coverslips ( $\varnothing 15 \mathrm{~mm}$, Hecht, Sondheim, Germany), harbored in a 24 well plate. After $24 \mathrm{~h}$, receptor expression was induced by adding $5 \mathrm{mg} / \mathrm{ml}$ tetracycline. Twenty-four hours later, cells were washed with warmed Ringer solution (138 mM NaCl, $5 \mathrm{mM} \mathrm{KCl,} 2 \mathrm{mM} \mathrm{CaCl} 2,1.5 \mathrm{mM} \mathrm{MgCl}_{2}, 10 \mathrm{mM}$ Hepes, $10 \mathrm{mM}$ Glucose, $\mathrm{pH} 7.3$ ) and incubated with $4 \mu \mathrm{mol} / \mathrm{L}$ fura-2 AM (Invitrogen) in Ringer solution at $37^{\circ} \mathrm{C}$ for $30 \mathrm{~min}$. A flow chamber was used to place a coverslip with cells loaded with fura- 2 onto the stage of an inverted microscope (Olympus IX70) equipped for epifluorescence. Cells were permanently rinsed with Ringer solution (warmed to $37^{\circ} \mathrm{C}$ ) at a flow rate of $1 \mathrm{ml} / 10 \mathrm{~s}$. Control and test solutions ( $400 \mu \mathrm{l}$ each) were applied at the same flow rate using a three-way valve system with connected syringes.

In a single experiment, cells were first rinsed for at least $5 \mathrm{~min}$ with Ringer solution, after which a control stimulus was applied (Ringer solution with $0.1 \%$ DMSO and $0.1 \% n$-Hexane). This procedure allowed us to monitor responses to DMSO or $n$-hexane and to eliminate spontaneously active cells from later data analysis. After rinsing cells for another $5 \mathrm{~min}$ with Ringer solution, test odorants were applied. Z11-16:Ald and plant odorants were diluted from stock solutions in $n$-hexane using Ringer solution with $0.1 \%$ DMSO. All dilutions were prepared freshly before imaging started. Following the application of test substances, the viability of the cell was tested by applying $10 \mathrm{mM}$ ATP in Ringer solution directly to the cell chamber. To monitor changes in the intracellular $\mathrm{Ca}^{2+}$ concentration in individual cells, light emission at $510 \mathrm{~nm}$ was measured over time following excitation 
at $340 \mathrm{~nm}$ and $380 \mathrm{~nm}$. Data analysis and acquisition were performed with the Metafluor imaging system and Metafluor 4 software (Visitron Systems, Puchheim, Germany). Changes in fluorescence intensity at $340 \mathrm{~nm} / 380 \mathrm{~nm}$ excitation were used as an index of increasing calcium concentrations. Ratios of fluorescence intensity for at least 30 cells per experiment were determined before $\left(F_{0}\right)$ and after stimulation ( $F$; peak of response). $F / F_{0}$ values of individual cells were determined and averaged in a single experiment.

\section{RESULTS \\ PLANT ODORANTS AFFECT PHEROMONE-INDUCED RESPONSES IN THE AL}

In order to analyze the interference between volatiles of host plants that are present in the environment of calling females and the major sex pheromone component Z11-16:Ald, we performed functional in vivo calcium imaging of the AL of male $H$. virescens. We compared odor-evoked calcium activity patterns after separately or simultaneously stimulating the antenna with Z11-16:Ald and different plant odorants. Stimulation of the antenna with Z11-16:Ald alone revealed clear calcium signals in the cumulus of the MGC, the place where Z11-16:Ald-reactive OSNs terminate (Figure 1A). In contrast, none of the plant odorants tested clearly activated the cumulus. Instead, the various plant odorants generated calcium signals in distinct yet partly overlapping sets of ordinary glomeruli (Figure 1A, upper row). This observation was substantiated in time course measurements (Figure 1B, upper row). Simultaneously stimulating the antenna with mixtures of the pheromone component and a plant odorant revealed different spatio-temporal activity patterns in the AL (Figure 1A, lower row). The combination of Z11-16:Ald and isoamyl acetate elicited calcium signals that were almost the sum of the responses obtained by stimulation with the single compounds. In contrast, application of Z11-16:Ald in combination with linalool or geraniol led to a significantly reduced pheromone-induced activity in the cumulus region, whereas the calcium response in the ordinary glomeruli appeared almost unaltered. These results were supported by the time courses of the measurements (Figure 1B, lower row).

The inhibitory effect of linalool and geraniol onto the pheromone-induced response in the cumulus was reproducible between different individuals (Figure 2). In addition, we observed a clear inhibitory effect for the two odorants Z3-hexenol and linalyl acetate. For isoamyl acetate, a slight inhibitory effect was observed in a few animals, but did not prove to be statistically significant (Figure 2). Thus, our experiments demonstrated that several, but not all plant odorants clearly inhibit the induced activity pattern in the first processing center for pheromone signals.

\section{INTERFERENCE OF PLANT ODORANTS WITH MOLECULAR ELEMENTS OF PHEROMONE SIGNALING}

The observation that plant odorants reduce pheromone-induced spiking activity of Ph-OSNs (Party et al., 2009; Hillier and Vickers, 2011; Deisig et al., 2012) suggests that the inhibitory effects of plant odorants on the Z11-16:Ald-evoked activity we monitored in the MGC (Figures 1 and 2) may result from an interference of plant odorants with molecular elements of pheromone detection in the antenna. It has recently been shown that in $H$. virescens the Z11-16:Ald detection involves the PBP HvirPBP2 and the PR HR13 (Grosse-Wilde et al., 2007). Therefore, we asked if plant-related odorants may affect these two components of the pheromone recognition system.

\section{PLANT ODORANTS DO NOT BIND TO HvirPBP2}

First, we have analyzed if plant odorants may be able to occupy the binding pocket of HvirPBP2 and thereby prevent binding of Z11-16:Ald. To estimate the binding of odorants to HvirPBP2, we conducted fluorescence displacement assays employing 1NPN as fluorescence reporter. When excited at $337 \mathrm{~nm}, 1-\mathrm{NPN}$ in aqueous buffer emits fluorescence only weakly. However, in a hydrophobic environment, such as the hydrophobic binding pocket of PBPs (Sandler et al., 2000), the fluorescence intensity increases and the emission maximum blue-shifts. Accordingly, the titration of 1-NPN to HvirPBP2 in Ringer solution resulted in a large increase in fluorescence intensity (Figure 3A) and a shift of the emission maximum from $465 \mathrm{~nm}$ to $402 \mathrm{~nm}$ (not shown). The concentration-dependent binding of 1-NPN can be described by a hyperbolic curve (Figure 3A), which is consistent with a one-site binding model and a calculated $K_{\text {diss }}$ value of $1.4 \mu \mathrm{M}$.

To test the functionality of the assay system and the integrity of the purified HvirPBP2, we monitored the ability of Z11-16:Ald to displace 1-NPN (Figure 3B). We found that upon titration of the pheromone component, the 1-NPN fluorescence was reduced in a concentration-dependent manner, indicating the pheromone component had bound to the hydrophobic binding pocket of HvirPBP2. Half-maximum 1-NPN displacement was obtained at a pheromone component concentration of $0.8 \mu \mathrm{M}$. Calculation of the relative dissociation constant revealed a $K_{\text {diss }}$ of $0.33 \mu \mathrm{M}$. A binding affinity for pheromones in the micromolar range was also found for the PBPs of other insects (Plettner et al., 2000; Campanacci et al., 2001). Thus, the competitive 1-NPN displacement assay demonstrated that Z11-16:Ald binds to HvirPBP2; this finding confirms and extends previous results (Grosse-Wilde et al., 2007).

To address the question if plant odorants are able to occupy the binding pocket of HvirPBP2, we tested the ability of different plant volatiles to displace $1-N P N$. In most cases, plant odorants did not markedly decrease 1-NPN fluorescence even at the highest concentration (Figure 4). Displacement was seen only after application of higher doses of linalyl acetate or $\beta$-caryophyllene. Together these results indicate that plant odorants do not (linalool, geraniol, Z3-hexenol, and isoamyl acetate) or only very weakly (linalyl acetate and $\beta$-caryophyllene) bind to the hydrophobic binding pocket of HvirPBP2.

\section{PLANT ODORANTS DO NOT ALTER Z11-16:ALD BINDING TO HvirPBP2}

Despite the inability to displace $1-N P N$, it is possible that plant odorants could affect the Z11-16:Ald binding of HvirPBP2 in a different way; for example, acting as allosteric effectors plant odorants may bind outside the Z11-16:Ald binding pocket and cause conformational changes of HvirPBP2, which may alter pheromone binding in a non-competitive manner. 

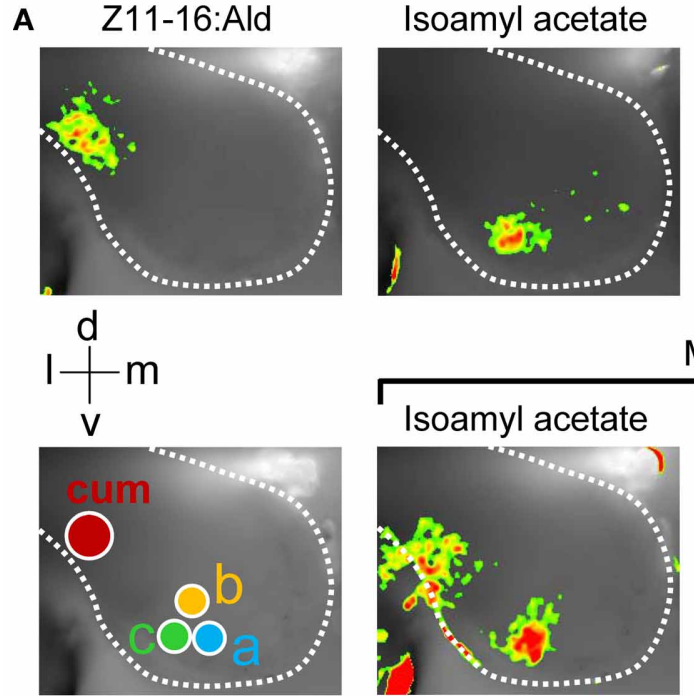

0

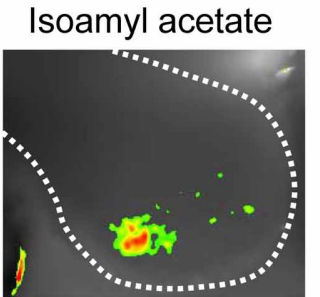

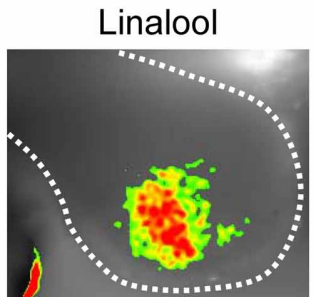

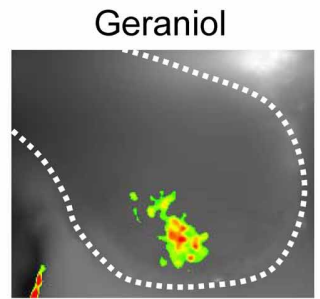

Mixture of Z11-16:Ald +
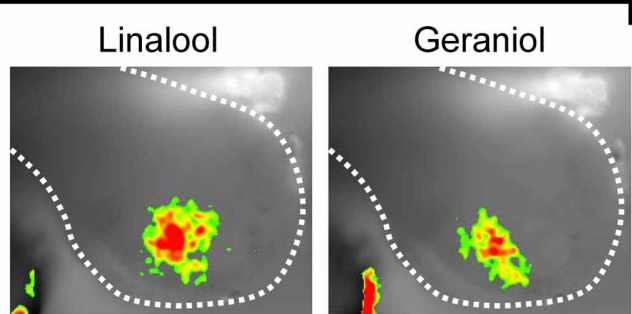

$\Delta F / F(\%)$
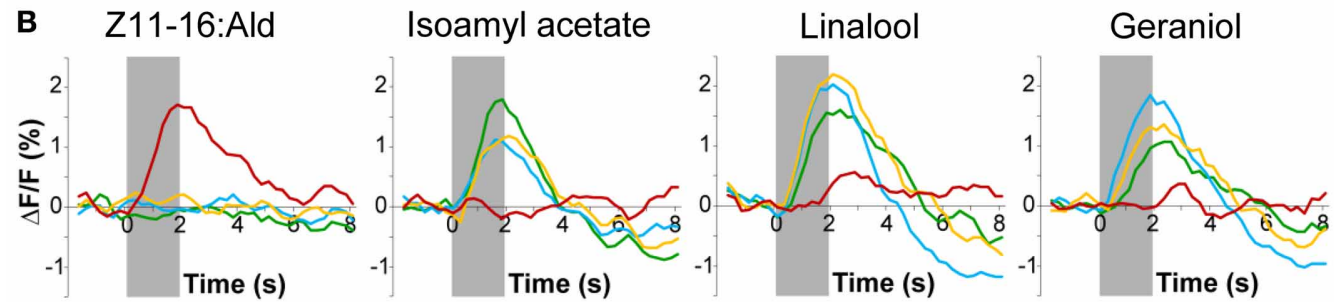

Mixture of Z11-16:Ald +

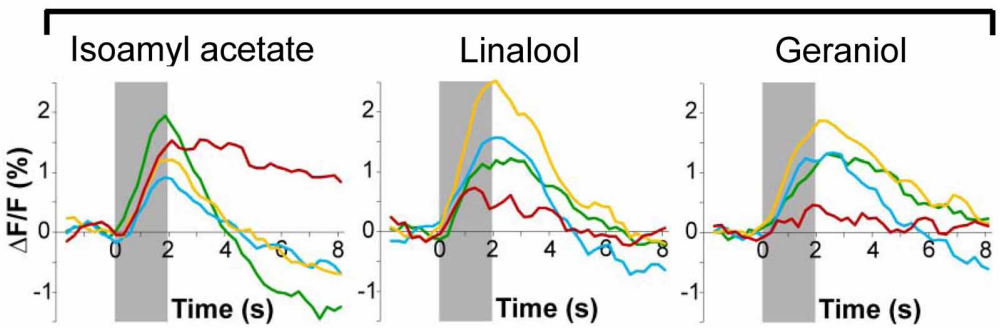

FIGURE 1 | Effect of plant odorants on pheromone-induced calcium signals in the moth antennal lobe. The antenna of a $H$. virescens male was stimulated separately with single compounds or simultaneously with Z11-16:Ald $(10 \mu \mathrm{g})$ and plant odorants [1:10 (v/v) diluted in mineral oil]. Activity patterns in the antennal lobe were monitored using calcium imaging. (A) Representative false-color coded spatial response patterns. The positions of the cumulus (cum) region in the macroglomerular complex and of three ordinary glomeruli $(\mathrm{a}-\mathrm{c})$ are indicated by colored circles. All images are scaled to the overall maximum of all measurements. Images represent $\Delta F / F$ (in \% change from background) superimposed onto the raw fluorescence images according to the scale below of one representative male moth. The directions medial $(\mathrm{m})$, lateral (I), dorsal (d), and ventral (v) are indicated. (B) Time courses of glomerular calcium responses shown as $\Delta F / F$ (in \%) of the cumulus (red line) and three ordinary glomeruli (yellow, green, and blue lines) as marked with circles in (A). The odor stimulation is indicated by the gray bar.
Searching for possible non-competitive effects of plant odorants on pheromone binding to HvirPBP2, we tested mixtures of Z11-16:Ald and odorants in a second series of 1-NPN displacement experiments. When the displacement curves for Z1116:Ald alone are compared to the curves obtained for pheromone plus plant odorant, no statistically significant difference in the binding curves were found (Figure 5). From these experiments we conclude that these plant odorants do not interfere with the ability of pheromones to bind to HvirPBP2 thus, indicating that it seems not to be a perturbed pheromone-binding protein which causes a plant odorant-mediated attenuation of the pheromone-induced response of Ph-OSNs on the antenna (Hillier and Vickers, 2011) and in the cumulus region of the AL

(Figures 1, 2). 


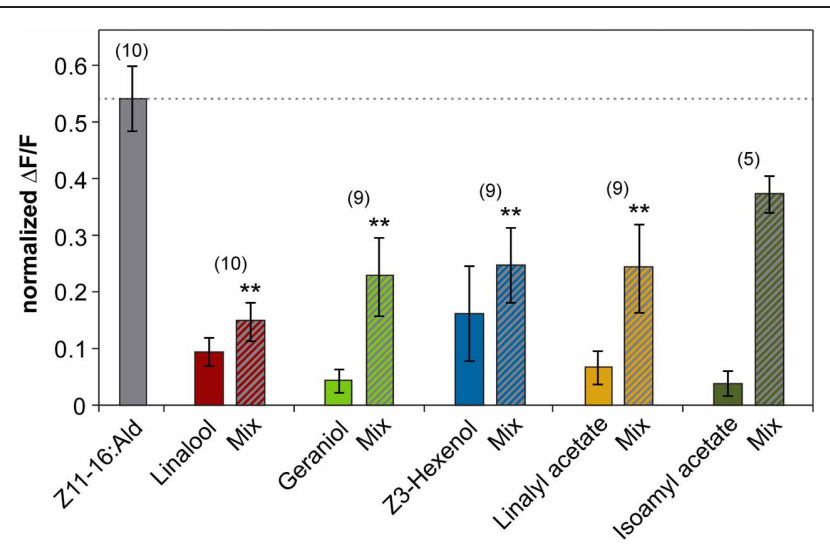

FIGURE 2 | Plant odorants inhibit the pheromone-induced activity in the cumulus region of the antennal lobe. Relative fluorescence changes in the cumulus region of the antennal lobe upon stimulation with Z11-16:Ald $(10 \mu \mathrm{g}$, gray bar), or with the plant odorant indicated [1:10 ( $/ \mathrm{v})$ diluted in mineral oil, colored bars] or with a mix of both (striped bars). Data represent the mean response including the standard error of mean (SEM) based on 5-10 H. virescens males. $\Delta F / F[\%]$ values have been normalized for each individual over all odors and glomeruli by setting the maximum response to 1 . All plant odorants except isoamyl acetate significantly reduce the pheromone-induced response in the cumulus $\left(^{* *} p<0.01\right.$; ANOVA followed by Dunnett Multiple Comparisons Test).
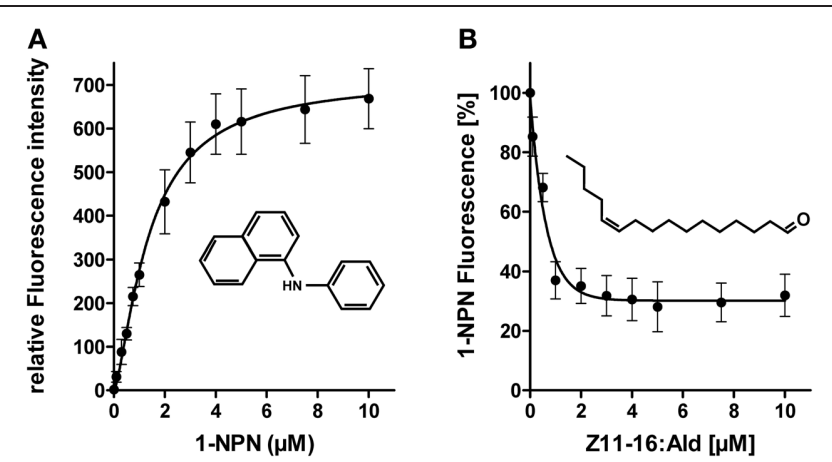

FIGURE 3 | 1-NPN binds to HvirPBP2 and is displaced by

Z11-16:Ald. (A) Relative fluorescence intensity as a function of 1-NPN concentration. HvirPBP2 in Ringer solution $(2 \mu \mathrm{M})$ was titrated with increasing amounts of $1-N P N$ to a final concentration of $10 \mu \mathrm{M}$. (B) Competitive fluorescence binding assay on HvirPBP2 $(2 \mu \mathrm{M}$ in Ringer solution) using 1-NPN $(2 \mu \mathrm{M})$. Maximum emission of 1-NPN fluorescence was monitored after increasing concentrations of Z11-16:Ald $(0-10 \mu \mathrm{M})$ were added. Fluorescence intensities at different pheromone component concentrations are shown as percentages of the maximum 1-NPN fluorescence in the absence of the pheromone component. Data represent the mean of three independent measurements. Standard deviations are indicated by error bars.

\section{PLANT ODORANTS AFFECT THE PHEROMONE-INDUCED RESPONSE OF HR13-EXPRESSING CELLS}

To determine whether plant odorants may affect the PR for Z11-16:Ald on the antenna, we next examined whether a HR13mediated pheromone response is altered in the presence of plant odorants. We used HEK293/Ga15 cells stably expressing HR13 and performed fura-2-based calcium imaging experiments in order to compare the responsiveness of the cells upon stimulation with the pheromone component or pheromone/plant odorant mixtures. In a first set of experiments we monitored changes in the level of intracellular $\left[\mathrm{Ca}^{2+}\right]$ of HR13 cells after stimulation with plant odorants used in the $\mathrm{AL}$ experiments (see above). Previous dose-response experiments (Grosse-Wilde et al., 2007) had shown that the threshold concentration for stimulating HR13 cells with Z11-16:Ald solubilized with DMSO in Ringer solution was about $10 \mathrm{pM}$. To detect any possible response of HR13 cells to plant odorants, we therefore used a 10,000-fold higher odorant concentration (100 nM). Stimulation of the HR13 cells with $100 \mathrm{nM}$ of the various plant odorants did not elicit any calcium signals that differed significantly from the control (Figure 6). In accordance with previous work (Grosse-Wilde et al., 2007), cells stimulated with a $1 \mathrm{nM}$ solution of Z11-16:Ald revealed a clear calcium response (Figure 6); such a response indicates the presence of a functional HR13 receptor protein, which binds the pheromone component and activates reaction cascades leading in turn to a rise in intracellular $\left[\mathrm{Ca}^{2+}\right]$.

Next, we analyzed the responses of HR13 cells to a stimulation with mixtures of Z11-16:Ald and single plant odorants. First, the odorant linalool was tested, which caused a strongly attenuated pheromone response at the level of the AL (Figures 1, 2). Stimulating HR13-expressing cells with $1 \mathrm{nM} \mathrm{Z11-16:Ald} \mathrm{elicited}$ a clear calcium response (Figure 7A), while linalool (100 nM) alone did not alter their calcium levels (Figure 7B). Interestingly, simultaneous application of Z11-16:Ald and linalool led to a significantly weaker calcium response (Figure 7C). To confirm the specificity of the linalool effect we used different ratios of Z1116:Ald to plant odorant $(1: 1,1: 10$, and 1:100) (Figure 7D). The results revealed that the pheromone-induced calcium responses of HR13 cells were significantly reduced at 10- and 100-fold excess of plant odorants. Even a 1:1 ratio of pheromone component to plant odorant resulted in a weaker, though not significant calcium signal. Thus, linalool reduced the pheromoneinduced calcium response of HR13 cells in a dose-dependent manner.

In a further series of calcium imaging experiments, we tested if other plant odorants that suppressed pheromone-induced activity in the cumulus region of the MGC (Figure 2) also affected the pheromone responses of HR13 cells. We found that a mixture containing 100-fold excess of linalyl acetate, Z3-hexenol, or geraniol significantly reduced the pheromone-induced calcium signal (Figure 8). In contrast, the odorant isoamyl acetate, which did not affect pheromone-evoked signals in the MGC, did not significantly change the pheromone-induced calcium responses of HR13 cells. Similarly, $\beta$-caryophyllene did not alter the pheromone-induced response (Figure 8). Together these results suggest that in $H$. virescens, the plant odorant-provoked suppression of pheromone-induced firing of Ph-OSNs as reported by Hillier and Vickers (2011) and the inhibition of the pheromoneinduced response in the Ph-OSNs projection area in the AL are mainly due to a plant odorant-dependent interference at the level of the PRs. 

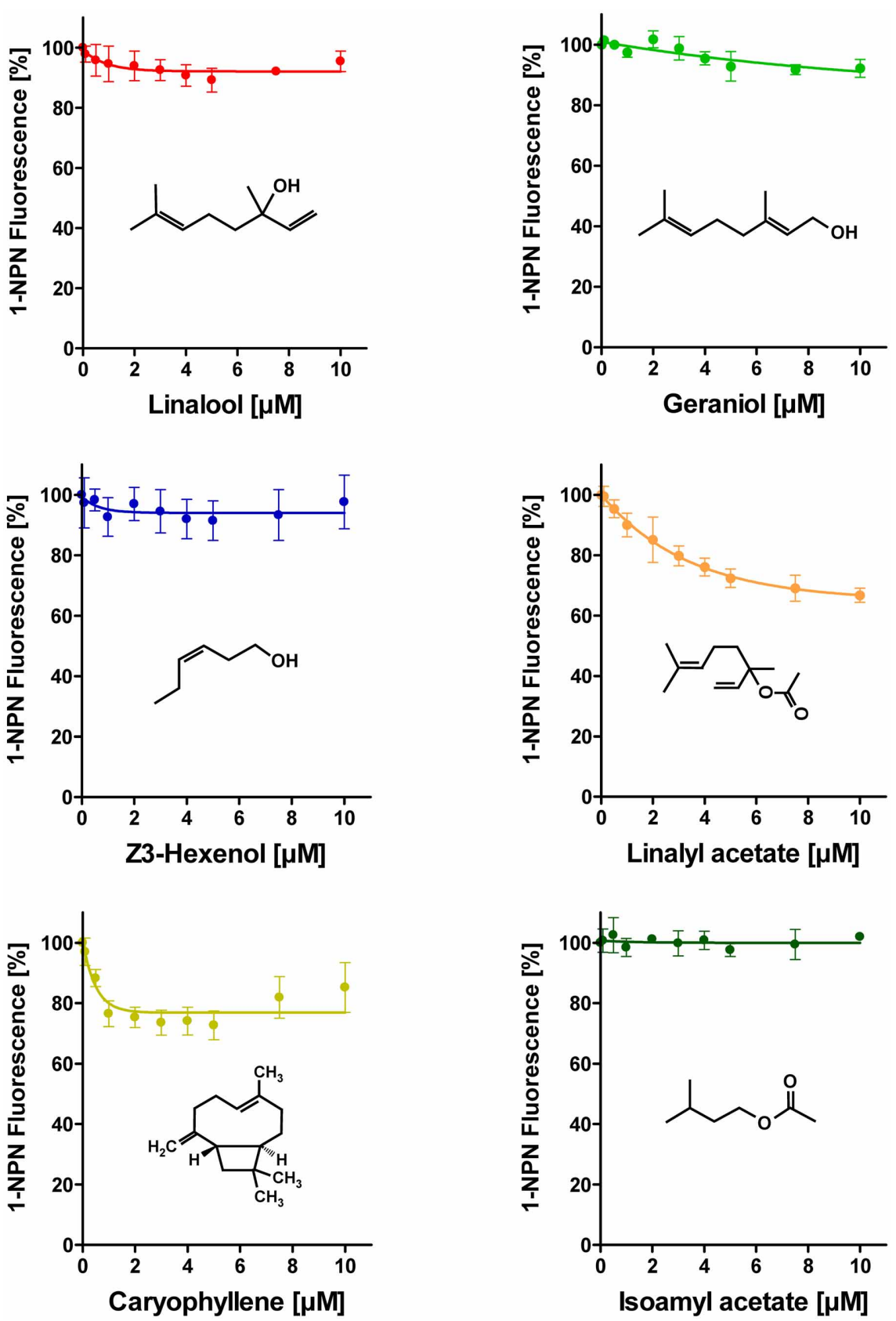

FIGURE 4 | Plant odorants do not bind or bind only very weakly to HvirPBP2. In competitive fluorescence-binding assays, a mixture of HvirPBP2 and 1-NPN (both at $2 \mu \mathrm{M}$ ) was titrated with increasing concentrations of the plant odorants indicated, while the emission of 1-NPN fluorescence was

monitored. Maximum fluorescence intensities are reported as percentages of the value in the absence of competitor (plant odorant). Data represent the mean of three independent measurements. Error bars indicate standard deviations.

\section{DISCUSSION}

\section{PLANT ODORANTS SUPPRESS PHEROMONE-EVOKED ACTIVITY IN THE} ANTENNAL LOBE

In this study we examined the effect of plant odorants on peripheral detection and primary central coding of a sex pheromone component using the noctuid moth $H$. virescens as a model. Functional imaging studies in the moth AL revealed that stimulation of the male antenna with the major sex pheromone component, Z11-16:Ald, in the presence of distinct plant volatiles, namely linalool, linalyl acetate, Z3-hexenol, and geraniol resulted in a significantly reduced pheromone-induced calcium signal in the cumulus region of the MGC, the projection area of $\mathrm{Z11}$ 16:Ald-specific Ph-OSNs. In contrast, the odorant isoamyl acetate did not have a significant effect. Interestingly this odorant is the only fruit odorant in our stimulus set and might not be of ecological relevance for a male moth, while the other compounds are 

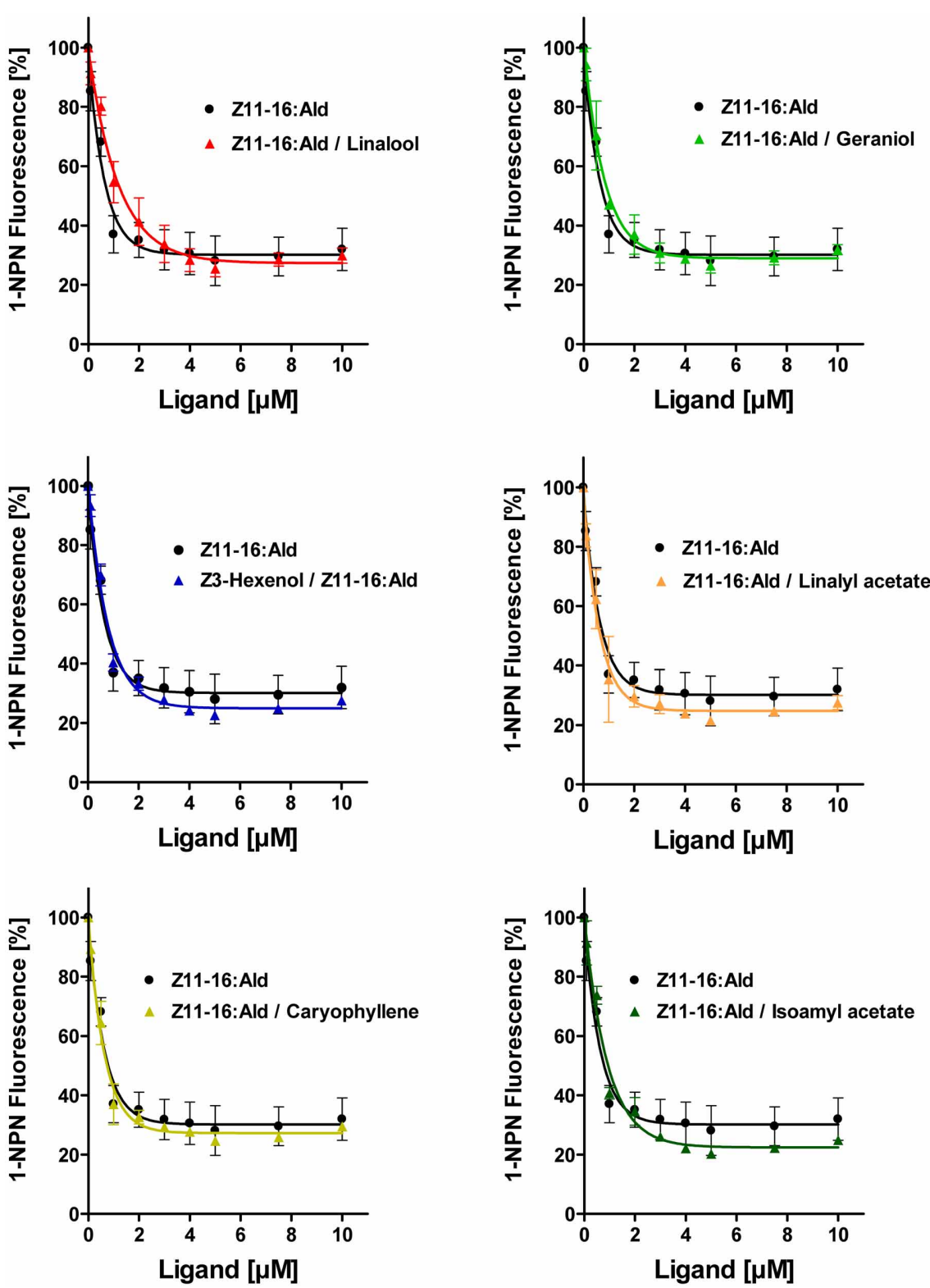

FIGURE 5 | Plant odorants do not interfere with the binding of

Z11-16:Ald to HvirPBP2. Competitive fluorescence binding assays were performed, employing HvirPBP2 and 1-NPN, both at $2 \mu \mathrm{M}$ concentration in Ringer solution. The maximum emission of 1-NPN fluorescence was monitored after increasing concentrations $(0-10 \mu \mathrm{M})$ of Z11-16:Ald were

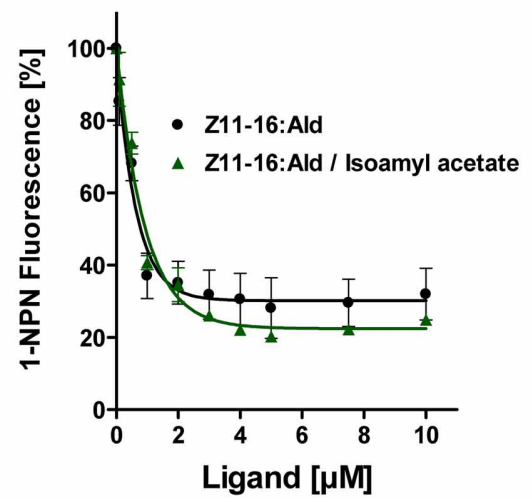

added and the plant odorants indicated (1:1 ratio). Maximum fluorescence intensities over concentration are shown as percentages of the value in the absence of the mixture. For comparison, the displacement curve determined for the pheromone component alone is depicted in addition to the displacement curves for the mixtures.

emitted by flowers or leafs. In vivo calcium imaging using bathapplied Calcium Green ${ }^{\mathrm{TM}}$ allowed us to monitor spatio-temporal changes in intracellular calcium levels in the AL, mainly reflecting the presynaptic calcium influx into OSNs (Galizia et al., 2000; Bisch-Knaden et al., 2012). In line with this observation, previous single sensillum recordings from the antenna of $H$. virescens (Hillier and Vickers, 2011) revealed that stimulation with mixtures of the pheromone component and linalool or Z3-hexenol strongly reduced the spiking activity of Z1116:Ald-specific Ph-OSNs. Contrary to $H$. virescens these plant odorants act synergistically with Z11-16:Ald in the heliothine moth Helicoverpa zea leading to an increased spiking activity (Ochieng et al., 2002). Whether these differences in mixture responses in the two heliothine species may be due to differences in their odorant receptors for Z11-16:Ald or result from other mechanisms have yet to be identified. Mentionable, in $H$. virescens an increase in spike frequency of Ph-OSNs after stimulation with a mixture of Z11-16:Ald and $\beta$-caryophyllene was noted (Hillier and Vickers, 2011). We did not test this compound in our AL experiments but found no $\beta$-caryophyllene-produced synergy in 


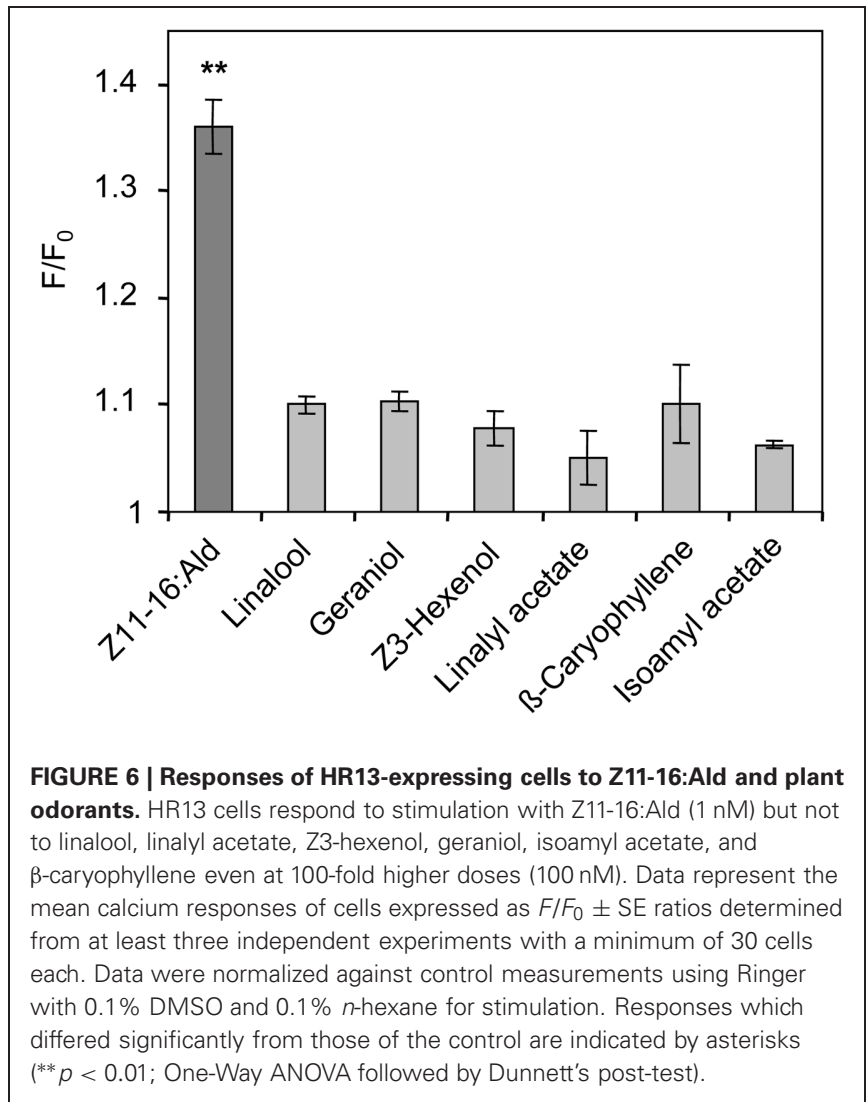

our experiments with HR13-expressing cells, suggesting that the plant odorant elicits a synergistic effect via a HR13-independent mechanism.

Interestingly, and similar to the results for linalool and Z3hexenol in $H$. virescens, a reduction of Ph-OSN spiking and a suppression of the pheromone-evoked activity in the AL was recently found for the plant odorant heptanal in the moth Agrotis ipsilon (Deisig et al., 2012). Although the reduced firing rate of OSNs correlate with reduced responses in the MGC we cannot rule out the possibility that inhibitory neural circuits, mediated by GABAergic local interneurons in the moth $\mathrm{AL}$, also contribute to the observed inhibition of pheromoneevoked signals. Since local interneurons form multiglomerular wide-field arborizations and connect the MGC with ordinary glomeruli (Christensen et al., 1993; Anton et al., 1997; Seki and Kanzaki, 2008), they might inhibit the MGC when a plant odor is applied. However, since our data strongly suggest that the inhibitory effect is already taking place at the PR site, we assume that the contribution of the inhibitory $\mathrm{AL}$ network to the observed effect is probably rather minor. Nevertheless, we will silence GABA-mediated inhibition in the AL in future experiments to investigate its contribution or feedback signaling.

\section{PLANT ODORANTS INTERFERE WITH PHEROMONE BINDING TO HR13}

Our data indicate that the attenuating effect of plant odorants in detection of the major sex pheromone component occurs at the level of the PR HR13. This is reminiscent of recent findings of the
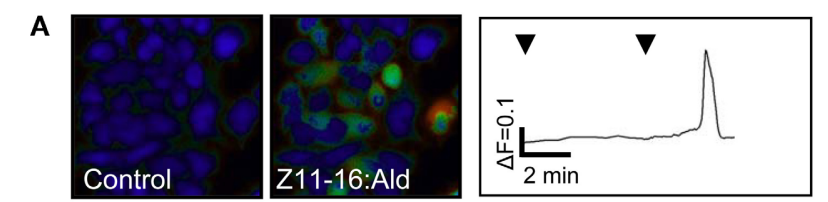

B
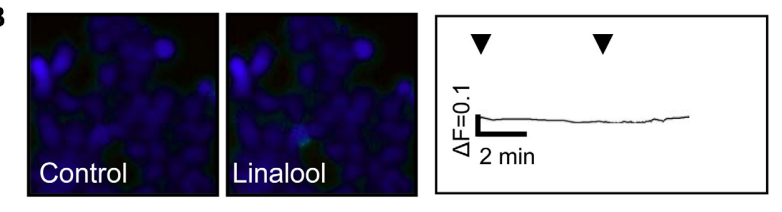

C
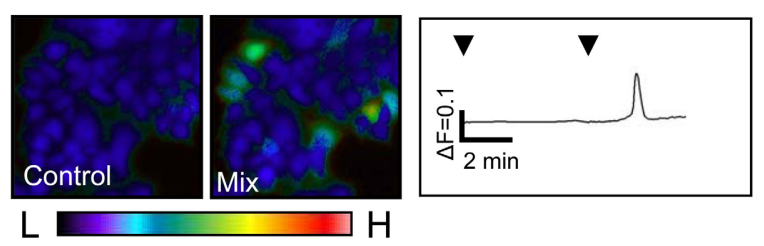

D

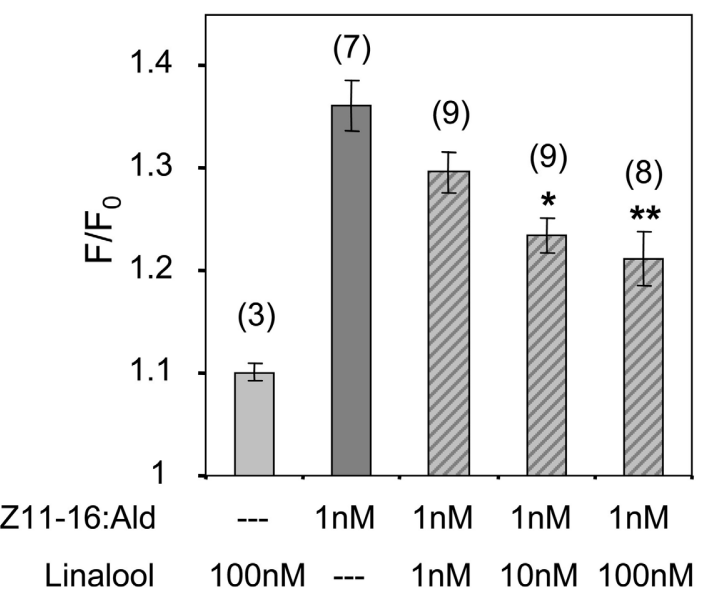

FIGURE 7 | Linalool reduces the responses of HR13-expressing cells to Z11-16:Ald. (A-C) Pseudocolor images on the left indicate calcium levels in HR13-expressing cells after the application of Ringer with $0.1 \%$ DMSO, $0.1 \% n$-hexane (control) or stimulation with solutions containing $1 \mathrm{nM}$ Z11-16:Ald (A), $100 \mathrm{nM}$ linalool (B) or a mixture of both (C). The color bar indicates low $(\mathrm{L})$ and high $(\mathrm{H})$ calcium concentration in blue and red, respectively. Calcium responses of representative cells from the experiments are shown to the right as changes of fura-2 fluorescence intensity ratios $(340 / 380 \mathrm{~nm})$ over time. HR13-expressing cells displayed clear calcium responses to Z11-16:Ald (A), whereas these cells did not respond to linalool (B) and showed reduced responses to a mixture (C) of the pheromone component and the plant odorant (ratio 1:100). (D) Responses of HR13-expressing cells to Z11-16:Ald/linalool mixtures at different ratios. Cell responses were monitored after stimulation with solutions containing $1 \mathrm{nM}$ Z11-16:Ald and 1, 10 or $100 \mathrm{nM}$ linalool, respectively. (For comparison, data for linalool and pheromone component alone were adopted from Figure 6.) HR13 cells do not respond to linalool $(100 \mathrm{nM})$ but show a clear calcium signal after stimulation with Z11-16:Ald $(1 \mathrm{nM})$. The pheromone-induced calcium response of the cells is significantly reduced in the presence of a 10- and 100-fold excess of linalool. Bars represent the mean responses of cells reported as $F / F_{0} \pm \mathrm{SE}$ ratios determined from 3 to 9 independent replicates with at least 30 cells in each experiment. Values have been normalized to the control. Responses to mixtures, which were significantly decreased compared to the response to the pheromone component alone, are indicated by asterisks $\left({ }^{*} p<0.05\right.$, ${ }^{* *} p<0.01$; One-Way ANOVA followed by Dunnett's post-test). 


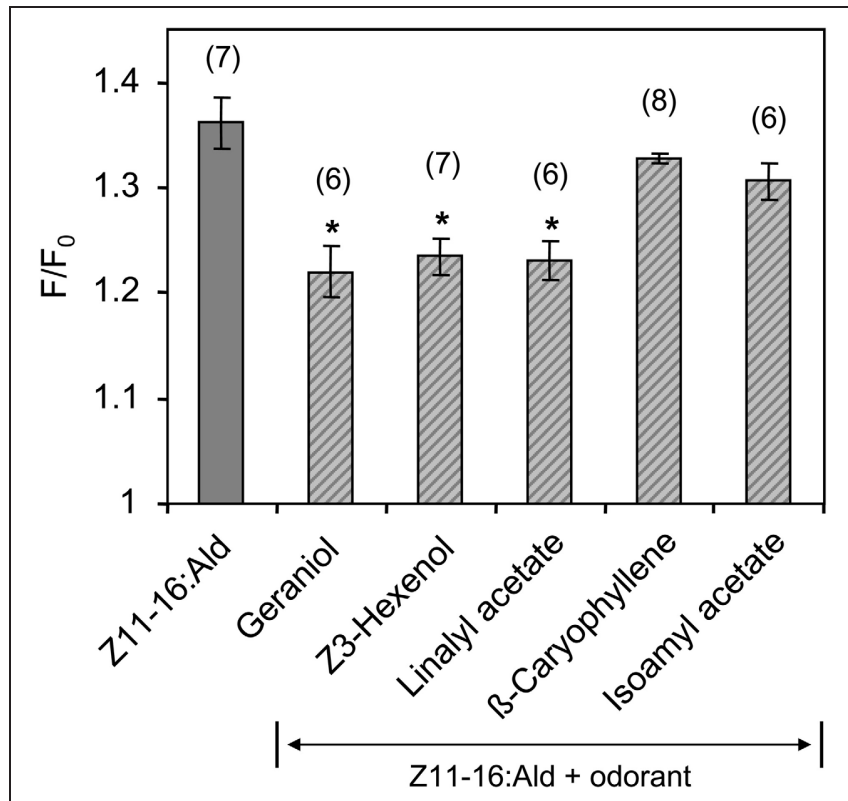

FIGURE 8 | Responses of HR13-expressing cells to mixtures of Z11-16:Ald with different plant odorants. HR13 cells were stimulated with solutions containing $1 \mathrm{nM}$ Z11-16:Ald and $100 \mathrm{nM}$ of the respective plant odorant (1:100 ratio). The pheromone response was significantly reduced in the presence of linalyl acetate, Z3-hexenol, and geraniol, but not in mixtures containing isoamyl acetate and $\beta$-caryophyllene. Data represent the mean calcium responses of cells expressed as $F / F_{0} \pm$ SE ratios determined from 6 to 8 independent experiments with a minimum of 30 cells each. Data were normalized to the control. Asterisks indicate mixture responses, which differed significantly from the responses to the pheromone component alone $(* p<0.05$; One-Way ANOVA followed by Dunnett's post-test).

fruit fly Drosophila melanogaster and the mosquitoes Anopheles gambiae and Aedes aegypti: in these insects, the responses of various olfactory receptor (OR) types to odorants were inhibited in the presence of several insect repellents (Ditzen et al., 2008; Bohbot and Dickens, 2010, 2012; Bohbot et al., 2011). For some mosquito ORs the data suggest a competitive antagonism or an allosteric inhibition of the repellents. Both mechanisms could also account for the interference of plant odorants with the Z1116:Ald response; plant odorants could occupy the pheromone binding site of the HR13 receptor or affect the receptor activity by allosteric inhibition.

Using a competitive binding assay, we confirmed and extended previous results demonstrating that HvirPBP2 is the binding protein for the major sex pheromone component (Grosse-Wilde et al., 2007). In contrast, none of the plant odorants was bound or did affect the binding of the pheromone component to HvirPBP2. These results suggest that plant odorants do not interfere with the solubilization and transfer of the major sex pheromone component in the sensillum lymph.

The finding that HvirPBP2 does not bind non-pheromone odorants in its ligand binding pocket raises the question of how inhibitory plant odorants overcome the aqueous sensillum lymph to elicit their effects at the receptor site. Although some of the compounds used here-for example, linalool—are soluble in aqueous solutions, others are hardly soluble or even non-soluble, e.g., linalyl acetate. Conceivably, the transfer of such compounds may be mediated by other proteins present in the sensillum lymph surrounding the HR13-expressing Ph-OSN. In support of this notion, previous in situ hybridization studies have shown that HvirPBP1 is co-expressed with HvirPBP2 in support cells associated with the same sensillum (Grosse-Wilde et al., 2007) and three PBPs coexist in pheromone responsive hairs of Antheraea polyphemus (Forstner et al., 2009). In addition, certain sensilla in the silk moth Bombyx mori co-express BmorPBP and the antennal binding protein X (ABPX) (Maida et al., 2005). Thus, HvirPBP1 or other yet not identified PBPs and OBPs coexisting in the sensillum lymph with HvirPBP2 may account for the solubilization and transfer of plant odorants.

Although non-pheromone odorants do not bind to the pheromone-binding pocket it cannot be excluded that they may interact with the surface of HvirPBP2 and thus be transported through the sensillum lymph. Considering such a possibility, one has to take into consideration that a plant odorant/PBP interaction may block conformational changes, which may be necessary for pheromone release (Wojtasek and Leal, 1999) or receptor activation by $\mathrm{PBP} /$ ligand complexes (Laughlin et al., 2008). In this way, the plant odorant/PBP interaction could directly contribute to the suppression of pheromone-evoked responses observed in single sensillum recordings (Party et al., 2009; Hillier and Vickers, 2011; Deisig et al., 2012) and calcium imaging of the AL (this study).

\section{ECOLOGICAL RELEVANCE OF PHEROMONE/PLANT ODORANT INTERFERENCE}

Female-released pheromones trigger and control upwind flight behavior and guide the male to the mating partner. According to our study and the work of others, the sex pheromone detection system of male moths seems unexpectedly susceptible to plant odorants in the environment. Most studies have reported that pheromone detection is suppressed in the presence of plant odorants (Party et al., 2009; Hillier and Vickers, 2011; Deisig et al., 2012).

With regard to a sensitive detection of the female-released pheromone and mate localization, the mostly found inhibition of the male pheromone detection system by plant odorants appears to be counterproductive. However, data suggest that suppression of the pheromone response by plant odorants may be of advantage. In electrophysiological studies of male antennae a background of plant odorants decreased the intensity of pheromone signals and improved the separation of pheromone pulses by the Ph-OSNs (Party et al., 2009). Furthermore, due to the reduced response rate both during and between pheromone pulses, a plant odorant background contributes to preserve the temporal structure of the pheromone signal (Rouyar et al., 2011). Because information encoded in the temporal structure of a pheromone plume is particularly important for orientation of male moths toward a pheromone source (Vickers, 2006), a higher odor background in the vicinity of a calling female sitting on a plant may positively affect mate localization by males approaching her. 


\section{ACKNOWLEDGMENTS}

The authors would like to thank the insect rearing unit at Bayer CropScience AG Frankfurt for providing Heliothis virescens pupae. We further thank Nelli Dick for excellent technical assistance, Katarina Dittrich, Maik Althans, and Hannes Merten for performing functional imaging experiments, and Sonja BischKnaden for statistical advice. This work was supported by the Deutsche Forschungsgemeinschaft, SPP1392 by grants to Jürgen Krieger (KR1786/4-1) and Silke Sachse (SA909/3-1), the Max Planck Society and a BMBF grant to Silke Sachse.

\section{REFERENCES}

Almaas, T. J., and Mustaparta, H. (1991). Heliothis virescens: response characteristics of receptor neurons in sensilla trichodea type 1 and type 2. J. Chem. Ecol. 17, 953-972.

Anton, S., Löfstedt, C., and Hansson, B. (1997). Central nervous processing of sex pheromones in two strains of the European corn borer Ostrinia nubilalis (Lepidoptera: Pyralidae). J. Exp. Biol. 200, 1073-1087.

Baker, T. C., Ochieng, S. A., Cosse, A. A., Lee, S. G., Todd, J. L., Quero, C., et al. (2004). A comparison of responses from olfactory receptor neurons of Heliothis subflexa and Heliothis virescens to components of their sex pheromone. J. Comp. Physiol. A 190, 155-165.

Ban, L., Scaloni, A., D'Ambrosio, C., Zhang, L., Yahn, Y., and Pelosi, P. (2003). Biochemical characterization and bacterial expression of an odorant-binding protein from Locusta migratoria. Cell. Mol. Life Sci. 60, 390-400.

Berg, B. G., Almaas, T. J., Bjaalie, J. G., and Mustaparta, H. (1998). The macroglomerular complex of the antennal lobe in the tobacco budworm moth Heliothis virescens: specified subdivision in four compartments according to information about biologically significant compounds. J. Comp. Physiol. A 183, 669-682.

Bisch-Knaden, S., Carlsson, M. A., Sugimoto, Y., Schubert, M., Missbach, C., Sachse, S., et al. (2012). Olfactory coding in five moth species from two families. J. Exp. Biol. 215, 1542-1551.

Bohbot, J. D., and Dickens, J. C. (2010). Insect repellents: modulators of mosquito odorant receptor activity. PLoS ONE 5:e12138. doi: 10.1371/journal.pone.0012138

Bohbot, J. D., and Dickens, J. C. (2012). Odorant receptor modulation: ternary paradigm for mode of action of insect repellents. Neuropharmacology 62, 2086-2095.

Bohbot, J. D., Fu, L., Le, T. C., Chauhan, K. R., Cantrell, C. L., and Dickens, J. C. (2011). Multiple activities of insect repellents on odorant receptors in mosquitoes. Med. Vet. Entomol. 25, 436-444.
Campanacci, V., Krieger, J., Bette, S., Sturgis, J. N., Lartigue, A., Cambillau, C., et al. (2001). Revisiting the specificity of Mamestra brassicae and Antheraea polyphemus pheromone-binding proteins with a fluorescence binding assay. J. Biol. Chem. 276, 20078-20084.

Carde, R. T., and Willis, M. A. (2008). Navigational strategies used by insects to find distant, wind-borne sources of odor. J. Chem. Ecol. 34, 854-866.

Carey, A. F., and Carlson, J. R. (2011). Insect olfaction from model systems to disease control. Proc. Natl. Acad. Sci. U.S.A. 108, 14849-14854.

Chaffiol, A., Kropf, J., Barrozo, R. B., Gadenne, C., Rospars, J. P., and Anton, S. (2012). Plant odour stimuli reshape pheromonal representation in neurons of the antennal lobe macroglomerular complex of a male moth. J. Exp. Biol. 215, 1670-1680.

Christensen, T. A., Waldrop, B. R. Harrow, I. D., and Hildebrand, J. G. (1993). Local interneurons and information processing in the olfactory glomeruli of the moth Manduca sexta. J. Comp. Physiol. A $173,385-399$.

David, C. T., Kennedy, J. S., and Ludlow, A. R. (1983). Finding of a pheromone source by gypsy moths released in the field. Nature 303 804-806.

Deisig, N., Kropf, J., Vitecek, S. Pevergne, D., Rouyar, A., Sandoz, J. C., et al. (2012). Differential interactions of sex pheromone and plant odour in the olfactory pathway of a male moth. PLoS ONE 7:e33159. doi: 10.1371/journal.pone.0033159

De Moraes, C. M., Mescher, M. C., and Tumlinson, J. H. (2001). Caterpillar-induced nocturnal plant volatiles repel conspecific females. Nature 410, 577-580.

Ditzen, M., Pellegrino, M., and Vosshall, L. B. (2008). Insect odorant receptors are molecular targets of the insect repellent DEET. Science $319,1838-1842$.

Forstner, M., Breer, H., and Krieger, J. (2009). A receptor and binding protein interplay in the detection of a distinct pheromone component in the silkmoth Antheraea polyphemus. Int. J. Biol. Sci. 5, 745-757.
Galizia, C. G., and Menzel, R. (2000). Odour perception in honeybees: coding information in glomerular pattern. Curr. Opin. Neurobiol. 10, 504-510.

Galizia, C. G., Sachse, S., and Mustaparta, H. (2000). Calcium responses to pheromones and plant odours in the antennal lobe of the male and female moth Heliothis virescens. J. Comp. Physiol. A 186, 1049-1063.

Grosse-Wilde, E., Gohl, T., Bouche, E., Breer, H., and Krieger, J. (2007). Candidate pheromone receptors provide the basis for the response of distinct antennal neurons to pheromonal compounds. Eur. J. Neurosci. 25, 2364-2373.

Grosse-Wilde, E., Stieber, R., Forstner M., Krieger, J., Wicher, D., and Hansson, B. S. (2010). Sexspecific odorant receptors of the tobacco hornworm Manduca sexta. Front. Cell. Neurosci. 4:22. doi: 10.3389/fncel.2010.00022

Grosse-Wilde, E., Svatos, A., and Krieger, J. (2006). A pheromonebinding protein mediates the bombykol-induced activation of a pheromone receptor in vitro. Chem. Senses 31, 547-555.

Hallem, E. A., and Carlson, J. R. (2006). Coding of odors by a receptor repertoire. Cell 125, 143-160.

Hansson, B. S. (1995). Olfaction in Lepidoptera. Experientia 51, 1003-1027.

Hansson, B. S., and Anton, S. (2000). Function and morphology of the antennal lobe: new developments. Annu. Rev. Entomol. 45, 203-231.

Hansson, B. S., Carlsson, M. A., and Kalinova, B. (2003). Olfactory activation patterns in the antennal lobe of the sphinx moth, Manduca sexta. J. Comp. Physiol. A Neuroethol. Sens. Neural Behav. Physiol. 189, 301-308.

Hansson, B. S., Ljungberg, H., Hallberg, E., and Lofstedt, C. (1992). Functional specialization of olfactory glomeruli in a moth. Science 256, 1313-1315.

Hansson, B. S., and Stensmyr, M. C. (2011). Evolution of insect olfaction. Neuron 72, 698-711.

Hillier, N. K., Kleineidam, C., and Vickers, N. J. (2005). Physiology and glomerular projections of olfactory receptor neurons on the antenna of female Heliothis virescens (Lepidoptera: Noctuidae) responsive to behaviorally relevant odors. J. Comp. Physiol. A. Neuroethol. Sens. Neural Behav. Physiol. 192, 199-219.

Hillier, N. K., and Vickers, N. J. (2007). Physiology and antennal lobe projections of olfactory receptor neurons from sexually isomorphic sensilla on male Heliothis virescens. Comp. Physiol. A Neuroethol. Sens. Neural Behav. Physiol. 193, 649-663.

Hillier, N. K., and Vickers, N. J. (2011). Mixture interactions in moth olfactory physiology: examining the effects of odorant mixture, concentration, distal stimulation, and antennal nerve transection on sensillar responses. Chem. Senses 36, 93-108.

Kesselmeier, J., and Staudt, M. (1997). Biogenic volatile organic compounds (VOC) an overview on emission, physiology and ecology. J. Atmos. Chem. 33, 22-88.

Krieger, J., Gaenssle, H., Raming, K., and Breer, H. (1993). Odorant binding proteins of Heliothis virescens. Insect Biochem. Mol. Biol. 23, 449-456.

Krieger, J., Grosse-Wilde, E., Gohl, T., Dewer, Y. M. E., Raming, K., and Breer, H. (2004). Genes encoding candidate pheromone receptors in a moth (Heliothis virescens). Proc. Natl. Acad. Sci. U.S.A. 101, 11845-11850.

Kuebler, L. S., Schubert, M., Karpati, Z., Hansson, B. S., and Olsson, S. B. (2012). Antennal lobe processing correlates to moth olfactory behavior. J. Neurosci. 32, 5772-5782.

Laughlin, J. D., Ha, T. S., Jones, D. N., and Smith, D. P. (2008). Activation of pheromone-sensitive neurons is mediated by conformational activation of pheromone-binding protein. Cell 133, 1255-1265.

Leal, W. S. (2003). "Proteins that make sense," in Insect Pheromone Biochemistry and Molecular Biology. The Biosynthesis and Detection of Pheromones and Plant Volatiles, eds G. Blomquist and R. Vogt (London: Elsevier Academic Press), 447-476.

Lei, H., and Vickers, N. (2008). Central processing of natural odor mixtures in insects. J. Chem. Ecol. 34, 915-927. 
Maida, R., Mameli, M., Muller, B., Krieger, J., and Steinbrecht, R. A. (2005). The expression pattern of four odorant-binding proteins in male and female silk moths, Bombyx mori. J. Neurocytol. 34, 149-163.

Müller, K., Pelzing, M., Gnauk, T., Kappe, A., Teichmann, U., Spindler, G., et al. (2002). Monoterpene emissions and carbonyl compound air concentration during blooming period of rape (Brassica napus). Chemosphere 49, 1247-1256.

Nakagawa, T., Sakurai, T., Nishioka, T., and Touhara, K. (2005). Insect sex-pheromone signals mediated by specific combinations of olfactory receptors. Science 307, 1638-1642.

Namiki, S., Iwabuchi, S., and Kanzaki, R. (2008). Representation of a mixture of pheromone and host plant odor by antennal lobe projection neurons of the silkmoth Bombyx mori. J. Comp. Physiol. A Neuroethol. Sens. Neural Behav. Physiol. 194, 501-515.

Ochieng, S. A., Park, K. C., and Baker, T. C. (2002). Host plant volatiles synergize responses of sex pheromone-specific olfactory receptor neurons in male Helicoverpa zea. J. Comp. Physiol. A Neuroethol. Sens. Neural Behav. Physiol. 188, 325-333.

Oldham, N. J., Krieger, J., Breer, H., and Svatos, A. (2001). Detection and removal of an artefact fatty acid from the binding site of recombinant Bombyx mori pheromonebinding protein. Chem. Senses 26, 529-531.

Party, V., Hanot, C., Said, I., Rochat, D., and Renou, M. (2009). Plant terpenes affect intensity and temporal parameters of pheromone detection in a moth. Chem. Senses 34, 763-774.

Plettner, E., Lazar, J., Prestwich, E. G., and Prestwich, G. D. (2000). Discrimination of pheromone enantiomers by two pheromone binding proteins from the gypsy moth Lymantria dispar. Biochemistry 39, 8953-8962.

Qiao, H., He, X., Schymura, D., Field, L., Dani, F. R., Michelucci, E., et al. (2010). Cooperative interactions between odorant-binding proteins of Anopheles gambiae. Cell. Mol. Life Sci. 68, 1799-1813.

Rostelien, T., Stranden, M., BorgKarlson, A. K., and Mustaparta, H. (2005). Olfactory receptor neurons in two Heliothine moth species responding selectively to aliphatic green leaf volatiles, aromatic compounds, monoterpenes and sesquiterpenes of plant origin. Chem. Senses 30, 443-461.

Rouyar, A., Party, V., Presern, J., Blejec, A., and Renou, M. (2011). A general odorant background affects the coding of pheromone stimulus intermittency in specialist olfactory receptor neurones. PLoS ONE 6:e26443. doi: 10.1371/journal.pone. 0026443

Sandler, B. H., Nikonova, L., Leal, W. S., and Clardy, J. (2000). Sexual attraction in the silkworm moth: structure of the pheromone-bindingprotein-bombykol complex. Chem. Biol. 7, 143-151.

Schneider, D. (1992). 100 years of pheromone research/An essay on lepidoptera. Naturwissenschaften 79, 241-250.

Seki, Y., and Kanzaki, R. (2008). Comprehensive morphological identification and GABA immunocytochemistry of antennal lobe local interneurons in Bombyx mori. J. Comp. Neurol. 506, 93-107.

Skiri, H. T., Galizia, C. G., and Mustaparta, H. (2004). Representation of primary plant odorants in the antennal lobe of the moth Heliothis virescens using calcium imaging. Chem. Senses 29, 253-267.

Steinbrecht, R. A., and Gnatzy, W. (1984). Pheromone receptors in Bombyx mori and Antheraea pernyi. I. Reconstruction of the cellular organization of the sensilla trichodea. Cell Tissue Res. 235, 25-34.

Vickers, N. J. (2006). Winging it: moth flight behavior and responses of olfactory neurons are shaped by pheromone plume dynamics. Chem. Senses 31, 155-166.

Vickers, N. J., and Baker, T. C. (1997) Flight of Heliothis virescens males in the field in response to sexpheromone. Physiol. Entomol. 22, 277-285.

Vickers, N. J., Christensen, T. A., Mustaparta, H., and Baker, T. C. (1991). Chemical communication in heliothine moths. III. Flight behavior of male Helicoverpa zea and Heliothis virescens in response to varying ratios of intra- and interspecific pheromone compounds. J. Comp. Physiol. A 169, 275-280.

Vogt, R. G. (2003). "Biochemical diversity of odor detection: OBPs, ODEs and SNMPs," in Insect Pheromone Biochemistry and Molecular Biology. The Biosynthesis and Detection of Pheromones and Plant Volatiles, eds G. Blomquist and R. G. Vogt (London: Elsevier Academic Press), 391-445.

Vogt, R. G., and Riddiford, L. M. (1981). Pheromone binding and inactivation by moth antennae. Nature 293, 161-163.

Vosshall, L. B. (2008). Scent of a fly. Neuron 59, 685-689.

Wang, G., Carey, A. F., Carlson, J. R., and Zwiebel, L. J. (2010). Molecular basis of odor coding in the malaria vector mosquito Anopheles gambiae. Proc. Natl. Acad. Sci. U.S.A. 107, 4418-4423.

Wanner, K. W., Nichols, A. S., Allen, J. E., Bunger, P. L., Garczynski, S. F., Linn, C. E., et al. (2010). Sex pheromone receptor specificity in the European corn borer moth, Ostrinia nubilalis. PLoS ONE 5:e8685. doi: 10.1371/journal. pone. 0008685

Wojtasek, H., and Leal, W. S. (1999). Conformational change in the pheromone-binding protein from Bombyx mori induced by $\mathrm{pH}$ and by interaction with membranes. J. Biol. Chem. 274, 30950-30956.

Zhang, S., Maida, R., and Steinbrecht, R. A. (2001). Immunolocalization of odorant-binding proteins in noctuid moths (Insecta, Lepidoptera). Chem. Senses 26, 885-896.

Zhou, J. J., Zhang, G. A., Huang, W., Birkett, M. A., Field, L. M., Pickett, J. A., et al. (2004). Revisiting the odorant-binding protein LUSH of Drosophila melanogaster: evidence for odour recognition and discrimination. FEBS Lett. 558, 23-26.

Zwiebel, L. J., and Takken, W. (2004). Olfactory regulation of mosquitohost interactions. Insect Biochem. Mol. Biol. 34, 645-652.

Conflict of Interest Statement: The authors declare that the research was conducted in the absence of any commercial or financial relationships that could be construed as a potential conflict of interest.

Received: 27 July 2012; accepted: 20 September 2012; published online: 08 October 2012.

Citation: Pregitzer P, Schubert M, Breer $H$, Hansson BS, Sachse $S$ and Krieger $J$ (2012) Plant odorants interfere with detection of sex pheromone signals by male Heliothis virescens. Front. Cell. Neurosci. 6:42. doi: 10.3389/fncel. 2012.00042

Copyright (c) 2012 Pregitzer, Schubert, Breer, Hansson, Sachse and Krieger. This is an open-access article distributed under the terms of the Creative Commons Attribution License, which permits use, distribution and reproduction in other forums, provided the original authors and source are credited and subject to any copyright notices concerning any third-party graphics etc. 